\title{
Improvement of Pulmonary Function in Heart Failure Patients with Restrictive Patterns Undergoing Transcatheter Aortic Valve Replacement
}

\author{
Handan Basel Karacop' \\ Erdem Karacop ${ }^{2}$ \\ 'Bezmialem Foundation University, \\ Faculty of Medicine, Department of \\ Pulmonary Medicine, Istanbul, Turkey; \\ ${ }^{2}$ Bezmialem Foundation University, \\ Faculty of Medicine, Department of \\ Cardiology, Istanbul, Turkey
}

\begin{abstract}
Background: This study aimed to investigate the improvement of pulmonary function in heart failure patients with restrictive patterns undergoing transcatheter aortic valve replacement (TAVR). Methods: A total of 80 patients with heart failure and restrictive patterns undergoing TAVR due to severe aortic stenosis were included in this study. Spirometry and gas diffusion were assessed before and 4-6 months after TAVR. Pre- and post-TAVR measures were compared using paired $t$-tests.

Results: Spirometry demonstrated increased absolute and percentage predicted total lung capacity (TLC), forced vital capacity (FVC), residual volume (RV), forced expiratory volume in the first second (FEV1), and forced vital capacity (FVC). FEV1/FVC decreased due to a pronounced increase in FVC. Additionally, the diffusing capacity for carbon monoxide (DLCO) increased significantly.
\end{abstract}

Conclusion: Pulmonary function improves in heart failure patients with restrictive patterns undergoing TAVR.

Keywords: pulmonary function, heart failure, transcatheter aortic valve replacement

\section{Introduction}

The prevalence of left ventricular dysfunction is between $6 \%$ and $11 \%$ when the ejection fraction (EF) falls below 30\% in patients undergoing transcatheter aortic valve replacement (TAVR) for severe aortic stenosis. It can rise to $46 \%$ when the EF is between $30 \%$ and $50 \% .^{1-3}$ A negative prognostic impact of TAVR was reported in the FRANCE 2 registry for patients with clinical signs of heart failure. ${ }^{4}$

Two distinct spirometric patterns are described by the Global Initiative for Chronic Obstructive Lung Disease (GOLD). The common abnormality in these patterns is a forced expiratory volume in the first second (FEV1) of $<80 \%$. The restrictive pattern was defined as FEV1/forced vital capacity (FVC) ratio (FEV1/FVC) $>70 \%$, whereas the obstructive pattern was defined as FEV1/FVC $<70 \%{ }^{5}$ Decreased total lung capacity due to reduced lung compliance was the main component of restriction. It is associated with an impaired functional status and frailty in older patients. ${ }^{5}$ Obstructive patterns are well documented, especially in chronic obstructive pulmonary disease (COPD). However, restrictive patterns in heart failure have not been well characterized in the literature. The mortality is higher in older adults with airflow restriction. Therefore, more attention should be paid to the diagnosis and prognosis of this condition.

Patients with heart failure develop pulmonary functional abnormalities ranging from minimal restriction to mixed restriction/obstruction. ${ }^{6}$ Several pathophysiological
Correspondence: Erdem Karacop Bezmialem Foundation University, Faculty of Medicine, Department of Cardiology, Adnan Menderes Avenue, Vatan Street, Fatih, Istanbul, 34093, Turkey

Tel + 902124531700

$\mathrm{Fax}+902126217580$

Email erdemkaracop@hotmail.com 
consequences of heart failure, including increased left ventricular filling pressure and pulmonary edema, may provoke these spirometric alterations. A restrictive pattern may emerge in the presence of decreased lung volume and due to the diffusing capacity for carbon monoxide (DLCO). However, the FEV1/FVC remained within the normal range. Bronchial edema may cause an obstructive pattern (low FEV1/FVC) in heart failure. The pulmonary function in heart failure patients with restrictive patterns undergoing TAVR has not been well studied. Moreover, the mutual interaction between heart failure with severe aortic stenosis and pulmonary function needs to be elucidated. There is mounting evidence that cardiac causes play an incontrovertible role in pre-TAVR pulmonary dysfunction in severe aortic stenosis.

Hence, we hypothesized that TAVR improves static and dynamic lung parameters, gas diffusion, and functional status. To our knowledge, there are no studies in the literature that have evaluated pulmonary function in pure heart failure patients undergoing TAVR. We sought to investigate the pulmonary function in this setting.

\section{Materials and Methods}

\section{Study Location}

The institution at which the work was performed: Bezmialem Foundation University, Faculty of Medicine, Department of Cardiology, Istanbul, Turkey.

\section{Study Population}

A total of 220 patients who underwent transfemoral TAVR due to severe aortic stenosis between 2013 and 2016 were retrospectively analyzed. A flowchart of the search strategy is shown in Figure 1. A total of 167 patients had a New York Heart Association (NYHA) class II to IV and an $\mathrm{EF} \leq 35 \%$. Among these, 103 patients had an FEV1 $<80 \%$ and FEV1/FVC ratio $>70 \%$. Twenty-three patients were excluded from the study. Finally, 80 consecutive patients (mean age: $79.79 \pm 8.47$ years) were enrolled in the study. Blood pressure higher than 140/90 $\mathrm{mmHg}$ and prior antihypertensive drug use were diagnosed as hypertension. The measurement should be verified at least three times in all patients. A fasting blood glucose level of $7.0 \mathrm{mmol} / \mathrm{L}$ or higher and prior antidiabetic drug use were diagnosed as diabetes mellitus. Total cholesterol levels of $5.2 \mathrm{mmol} / \mathrm{L}$ or higher and prior statin use were diagnosed as hyperlipidemia. The main diagnostic criteria for coronary artery disease were as follows: a)
220 patients who underwent TAVR between $2013-2016$

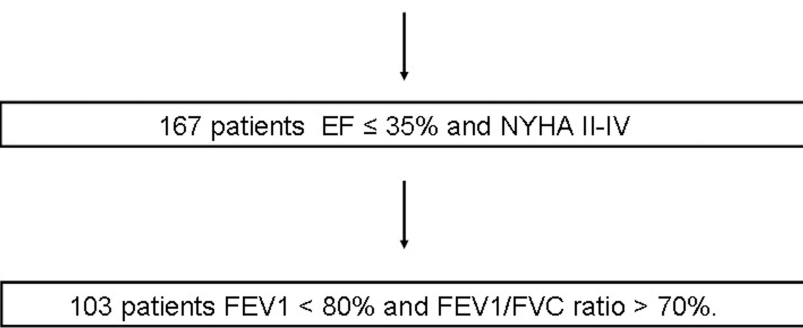

103 patients $\mathrm{FEV} 1<80 \%$ and $\mathrm{FEV} 1 / \mathrm{FVC}$ ratio $>70 \%$.

23 patients were excluded

80 patients included

Figure I Flow chart of search strategy

Abbreviations: EF, ejection fraction; NYHA, New York Heart Association; TAVR, transcatheter aortic valve replacement; FVC, forced vital capacity; FEVI, forced expiratory volume in first second.

Previous coronary angiography showed $\geq 70 \%$ stenosis in at least one major epicardial coronary vessel; b) The patient had a history of post-coronary artery bypass graft or percutaneous coronary intervention. The components of stroke included transient ischemic attack and stroke (ischemic or hemorrhagic). Smoking status was defined as smoking prior to the hospitalization. Peripheral vascular disease was defined as claudication, carotid stenosis, planned or completed vascular surgery, or X-ray intervention. We calculated the estimated glomerular filtration rate using the Chronic Kidney Disease Epidemiology Collaboration equation. Patients with any of the following were excluded: obstructive lung disease, intrinsic restrictive lung impairment (ie, interstitial lung diseases such as pneumoconiosis, pulmonary fibrosis, sarcoidosis, idiopathic pulmonary fibrosis, hypersensitivity pneumonitis causing inflammation and scarring of the lung tissue), extrinsic restrictive lung impairment (ie, neuromuscular disease affecting respiratory muscle function such as muscular dystrophy, phrenic neuropathy, and other nerve and muscle disorders, musculoskeletal system abnormalities such as scoliosis, kyphosis, and chest wall deformities cause incomplete expansion of the lungs), malignancy, end-stage hepatic and renal failure, and acute cardiovascular or cerebrovascular events within the preceding three months. Study was approved by Bezmialem University Ethics Committee and it was conducted in accordance with ethical principles described by the Declaration of Helsinki. The research involves no more than minimal risk to subjects hence patient consent to review their 
medical records was not required by the Bezmialem University Ethics Committee. Additionally, patient data confidentiality is adequately protected.

\section{Data Collection}

Demographic, clinical, and laboratory data were recorded from a local database. The medical history, physical findings, and laboratory data were evaluated at every clinical visit. Patients were regularly followed up in the cardiology outpatient clinic at Bezmialem University. All patients had spirometric data. Pulmonary function measurements, echocardiography, and electrocardiography were recorded at baseline 1-2 days before TAVR. They were repeated 4-6 months after TAVR.

\section{Echocardiography}

Transthoracic echocardiography (VIVID 7 Dimension Cardiovascular Ultrasound System) (Vingmed-General Electric, Horten, Norway) was performed at least twice (before the procedure and 4-6 months after the procedure) for each patient. The left ventricular diameters were measured by M-mode, and the left atrial area was calculated using the apical four-chamber view. Additionally, the Simpson method was the method of choice for calculating the EF. The aortic valve area and aortic mean gradient were calculated using valve planimetry and Doppler echocardiography. If the planimetric area was smaller than $1 \mathrm{~cm}^{2}$ and the mean transaortic gradient was greater than $40 \mathrm{mmHg}$, the stenosis was classified as severe. All echocardiographic examinations were performed by two experienced cardiologists in the Bezmialem University echocardiography laboratory.

\section{Device and Procedure}

The procedure was performed via the transfemoral route under local anesthesia with conscious sedation. All patients received supplemental oxygen by face mask to maintain arterial oxygen saturation higher than $90 \%$. A Medtronic CoreValve prosthesis (Medtronic, Minneapolis, MN, USA) was implanted through an Amplatz Extra Stiff guidewire under temporary pacing at a rate of $90-120$ beats $/ \mathrm{min}$. Pre- and post-implantation balloon valvuloplasty was undertaken at the discretion of an interventional cardiologist. Valve position, paravalvular leakage, rhythm disturbances, and peripheral complications were evaluated comprehensively using fluoroscopy. Aspirin and clopidogrel were administered as antiplatelet drugs for one year after the procedure.

\section{Pulmonary Function}

A spirometer (SensorMedics Corporation, Yorba Linda, CA, USA) was used to evaluate pulmonary function in the Pulmonary Medicine Department of Bezmialem University. The same device was used for all patients. Recent myocardial infarction and cranial, ophthalmological, thoracic, and abdominal surgery were absolute contraindications for performing spirometry. NHANES III described age-, sex-, and race-specific normalized reference values for spirometric parameters. Additionally, we calculated the FEV1 and FVC from the NHANES III equations. ${ }^{7}$ Abnormal lung functions included \% FEV1/ FVC or FVC below the lower limit of normal (ie, 5th percentile) and were further classified into obstructive and restrictive patterns. The obstructive pattern was defined as FEV $1<80 \%$ and FEV1/FVC $<70 \%$. On the other hand, the restrictive pattern was defined as FEV1 $<80 \%$ and FEV1/FVC $>70 \% .{ }^{8}$ Total lung capacity, FEV1, FVC, and residual volume were measured. We collected DLCO measurements according to the standards of the American Thoracic Society. ${ }^{9}$

\section{Statistical Analysis}

Data were analyzed using SPSS 17 (SPSS Inc., Chicago, IL, USA). Continuous parameters were expressed as mean \pm standard deviation, and categorical parameters were expressed as numbers and percentages. After testing the normality of distribution using the Shapiro-Wilk test, continuous variables were evaluated using either the paired sample $t$-test or the Mann-Whitney $U$-test. Moreover, the chi-squared test was performed for categorical variables. Statistical significance was set at $\mathrm{p}<0.05$.

\section{Results}

The study population consisted of 80 patients with a mean age of $79.79 \pm 8.47$ years. The gender distribution was nearly equal $(\mathrm{m} / \mathrm{f}=0.95)$. They were predominantly in the NYHA class III (73.8\%), with a low EF $(29.41 \pm 4.86 \%)$, markedly dilated left ventricle $(62.71 \pm 6.59 \mathrm{~mm})$ and pulmonary hypertension ( $45.89 \pm 14.75 \mathrm{mmhg}$ ). The baseline characteristics are summarized in Table 1. The pre-TAVR and postTAVR clinical and echocardiographic parameters are shown in Table 2. There were significant improvements in left ventricular function, pulmonary artery pressure, and NYHA status. Figure 2 shows pre- and post-TAVR NYHA functional class improvement $(3.01 \pm 0.51,2.50 \pm 0.63,0.001)$. Spirometry after TAVR demonstrated an increased absolute 
Table I Baseline Characteristics

\begin{tabular}{|l|l|}
\hline & $\mathbf{( N ~ = ~ 8 0 )}$ \\
\hline Age (years) & $79.79 \pm 8.47$ \\
\hline Gender (male/female) & $4 \mathrm{I} / 39$ \\
\hline NYHA class & \\
II (\%) & $10(12.4)$ \\
III (\%) & $59(73.8)$ \\
IV (\%) & $1 \mathrm{I}(13.8)$ \\
\hline GFR (mL/min/l.73m ${ }^{2}$ ) & $54.50 \pm 21.9 \mathrm{I}$ \\
Coronary artery disease (\%) & $44(55.0)$ \\
Smoking (\%) & $36(45.0)$ \\
Hypertension (\%) & $56(70.0)$ \\
Dyslipidemia (\%) & $8(10.0)$ \\
Peripheral vascular disease (\%) & $6(7.5)$ \\
Diabetes mellitus (\%) & $27(33.8)$ \\
Cerebrovascular accident (\%) & $3(3.8)$ \\
Logistic Euroscore & $16.85 \pm 5.84$ \\
\hline
\end{tabular}

Notes: Data is presented as means \pm SD or $n(\%)$.

Abbreviations: NYHA, New York Heart Association; GFR, glomerular filtration rate.

Table 2 Clinical and Echocardiographic Response to TAVR

\begin{tabular}{|c|c|c|c|}
\hline & PRE-TAVR & POST-TAVR & p Value \\
\hline EF (mean \%) & $29.41 \pm 4.86$ & $30.23 \pm 4.93$ & $P<0.001$ \\
\hline LVDD (mm) & $62.71 \pm 6.59$ & $62.10 \pm 6.87$ & $P<0.001$ \\
\hline PAP (mmhg) & $45.89 \pm 14.75$ & $40.61 \pm \mid 4.21$ & $P<0.001$ \\
\hline NYHA class & $3.01 \pm 0.51$ & $2.50 \pm 0.63$ & $P<0.001$ \\
\hline GFR $\left(\mathrm{mL} / \mathrm{min} / 1.73 \mathrm{~m}^{2}\right)$ & $54.50 \pm 21.91$ & $54.71 \pm 21.83$ & 0.280 \\
\hline \multicolumn{4}{|l|}{ Medication } \\
\hline ACE inhibitors/ARBs (\%) & $70(87.5)$ & $78(97.5)$ & 0.011 \\
\hline Beta blockers (\%) & 73 (9l.2) & $78(97.5)$ & 0.096 \\
\hline Diuretics (\%) & 73 (9l.2) & $77(96.2)$ & 0.208 \\
\hline Digoxin (\%) & $40(50.0)$ & $4 \mid(5 \mid .2)$ & 0.320 \\
\hline
\end{tabular}

Note: Data is presented as means \pm SD or $n(\%)$.

Abbreviations: EF, ejection fraction; LVDD, left ventricular diastolic diameter; PAP, pulmonary artery pressure; NYHA, New York Heart Association; GFR, glomerular filtration rate; $A C E$, angiotensin-converting enzyme; $A R B$, angiotensin receptor blocker.

and percentage predicted total lung capacity ( $3.90 \pm 0.37$ vs $4.61 \pm 0.26 \mathrm{~L}, \mathrm{p}<0.001$ and $64.56 \pm 2.84$ vs $80.20 \pm 4.19 \%$, $\mathrm{p}<0.001)$, FVC $(1.90 \pm 0.34$ vs $2.09 \pm 0.63 \mathrm{~L}, \mathrm{p}<0.001$ and $67.50 \pm 4.63$ vs $74.46 \pm 5.74 \%, p<0.001)$, residual volume $(1.47 \pm 0.7$ vs $1.69 \pm 0.53 \mathrm{~L}, \mathrm{p}<0.001$ and $64.43 \pm 3.85$ vs $75.73 \pm 5.26 \%, \mathrm{p}<0.001)$, FEV1 $(1.45 \pm 0.30$ vs $1.49 \pm 0.28$ $\mathrm{L}, \mathrm{p}<0.001$ and $59.54 \pm 3.43$ vs $60.73 \pm 3.19 \%$, p $<0.001)$, FVC $(1.90 \pm 0.34$ vs $2.09 \pm 0.63 \mathrm{~L}, \mathrm{p}<0.001$ and $67.50 \pm$ 4.63 vs $74.46 \pm 5.74 \%, p<0.001$ ) (Tables 3 and 4 ). Spirometry revealed decreased FEV1/FVC $(91.13 \pm 5.46$ vs $88.33 \pm 5.33 \%, \mathrm{p}=0.027)$ due to a pronounced increase in
FVC (Table 4). DLCO increased significantly $(10.04 \pm 0.51$ vs $10.84 \pm 0.39 \mathrm{~mL} / \mathrm{min} / \mathrm{mmHg}, \mathrm{p}<0.01$ and $42.40 \pm 4.62$ vs $46.74 \pm 2.00 \%, \mathrm{p}<0.001$ ) (Tables 3 and 4 ).

\section{Discussion}

The main finding of our study is that TAVR improves static (ie, total lung capacity, residual volume) and dynamic (ie, FEV1 and FVC) pulmonary functions, in accordance with increased lung conductance and volumes in heart failure patients with restrictive patterns. FEV1/ FVC decreased due to a pronounced increase in FVC. Additionally, the DLCO significantly increased. Spirometry showed minimal restrictive to mixed restrictive/obstructive pulmonary functional abnormalities in patients with heart failure. ${ }^{7-10}$ The inclusion criteria for the enrollment in this retrospective study were LVEF $\leq$ $35 \%$, NYHA class II to IV despite medical therapy, and FEV $1<80 \%$ and FEV1/FVC ratio $>70 \%$ in heart failure with reduced ejection fraction patients without obstructive pulmonary functions. The initial pulmonary function revealed a restrictive pattern with severely depressed lung volumes.

Increased left ventricular end-diastolic pressure leads to pulmonary edema and congestion in heart failure. In the acute phase, these changes result in cardiac decompensation. However, chronic elevation of the left ventricular filling pressure causes progressive pulmonary hypertension. Several pathophysiological consequences of heart failure, including low cardiac output, ${ }^{13}$ cardiomegaly, ${ }^{14}$ respiratory muscle weakness, ${ }^{12}$ chronic pulmonary congestion, and hypertension, ${ }^{11}$ may provoke abnormal pulmonary function. Additionally, left ventricular hypertrophy and left atrial enlargement may deepen the effect of heart failure, causing diastolic dysfunction in severe aortic stenosis. TAVR breaks this vicious cycle by increasing the forward transmission through the prosthetic valve.

Traditionally, decreased DLCO and FEV1/FVC $\geq 70 \%$ have been used to detect restrictive pulmonary physiology, as observed in patients with pure heart failure. However, the exact mechanism that explains the association between decreased lung volumes and TAVR has not been characterized in the literature. Magee et al postulated a moderate improvement in COPD severity in surgical aortic valve replacement (SAVR) and TAVR. ${ }^{15}$ They observed increased FEV1 and decreased brain natriuretic peptide (BNP) levels. The main reason for these alterations was the reversibility of airway obstruction due to edema in 


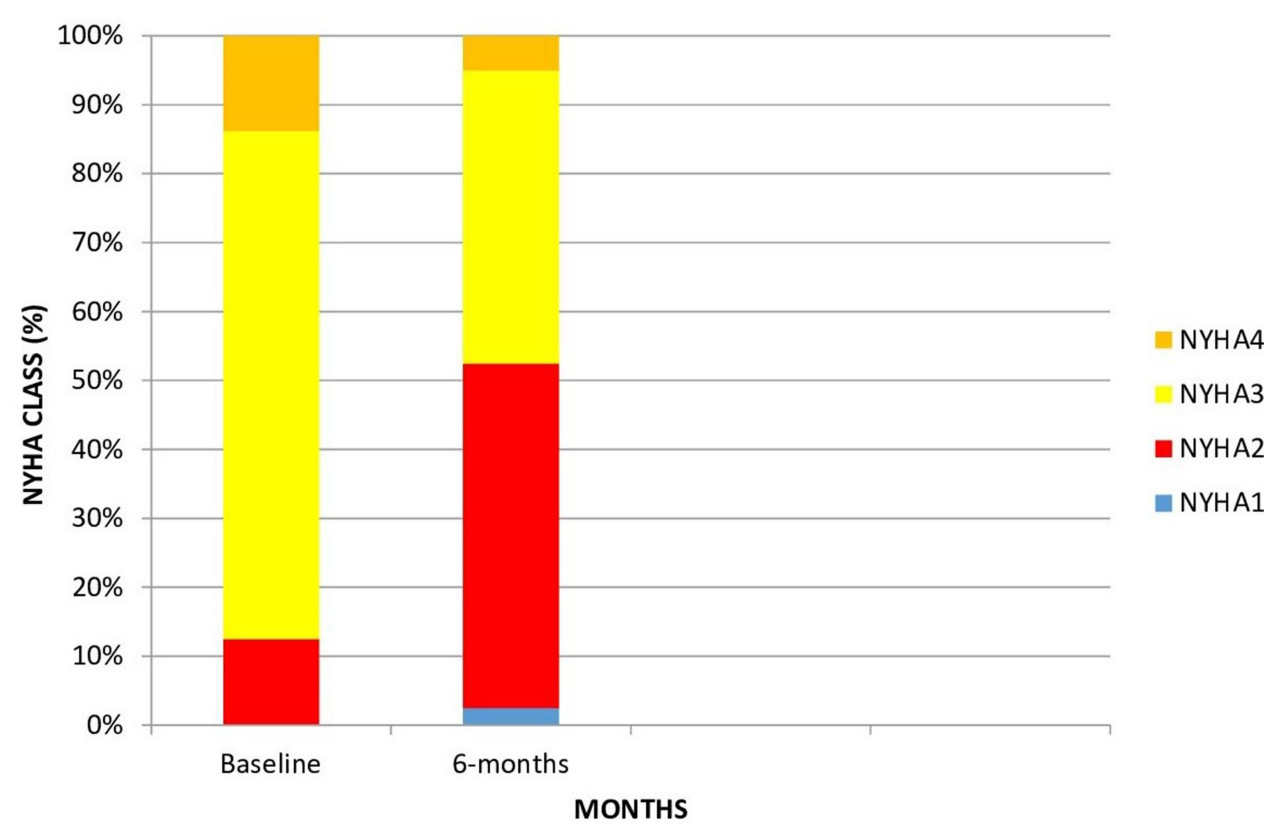

Figure 2 NYHA-class at baseline and 6-months postoperative. Abbreviation: NYHA, New York Heart Association.

heart failure. It is noteworthy that this study was conducted in patients with a typical obstructive pattern. Another study with COPD patients undergoing TAVR demonstrated decreased $\mathrm{BNP}$ and increased $\mathrm{EF}$ in all COPD categories, suggesting improved overall cardiac function. ${ }^{16}$ However, no change in DLCO has been reported. ${ }^{16}$ The main proposal was that restrictive lung physiology was not altered after TAVR. In contrast, we found a $4.34 \%$ increase in the DLCO. The main mechanism underlying this improvement could be related to the reversibility of the restrictive pattern under specific conditions.

Pulmonary artery systolic pressure (PASP) strongly predicts death and provides incremental and clinically relevant prognostic information among patients with heart failure ${ }^{17}$ and severe aortic stenosis. ${ }^{18}$ Conditions such as aortic stenosis, left ventricular dysfunction, mitral

Table 3 Pulmonary Function Tests (Absolute Values) $(n=80)$

\begin{tabular}{|l|l|l|l|}
\hline & PRE-TAVR & POST-TAVR & P Value \\
\hline Total lung capacity (L) & $3.90 \pm 0.37$ & $4.61 \pm 0.26$ & $<0.00 \mathrm{I}$ \\
Residual Volume (L) & $\mathrm{I} .47 \pm 0.75$ & $1.69 \pm 0.53$ & $<0.00 \mathrm{I}$ \\
FVC (L) & $1.90 \pm 0.34$ & $2.09 \pm 0.63$ & $<0.00 \mathrm{I}$ \\
FEV I (L) & $1.45 \pm 0.30$ & $1.49 \pm 0.28$ & $<0.00 \mathrm{I}$ \\
DLCO $(\mathrm{mL} / \mathrm{min} / \mathrm{mmHg})$ & $10.04 \pm 0.5 \mathrm{I}$ & $10.84 \pm 0.39$ & $<0.00 \mathrm{I}$ \\
\hline
\end{tabular}

Note: Data is presented as means \pm SD or $n(\%)$.

Abbreviations: FVC, forced vital capacity; FEVI, forced expiratory volume in first second; DLCO, diffusing capacity of the lungs for carbon monoxide. regurgitation, and diastolic dysfunction lead to increased LV end-diastolic pressure, resulting in elevated pressures in the pulmonary venous circulation and consecutively inducing arterial vasoconstriction and pulmonary arterial remodeling. ${ }^{17,19}$ Recent studies have reported that TAVR leads to systolic pulmonary artery pressure reduction with baseline pulmonary hypertension. In concordance with other studies, we found a significant decrease in the PASP. This may have a positive effect on pulmonary function.

We demonstrated a significant improvement in the NYHA class at six months in our study $(-0.51$ class $)$. Eight studies ${ }^{20-27}$ qualitatively reported improvements in the NYHA class after TAVR. In most studies, there was an average improvement of $\geq 1$ NYHA class after TAVR at 6-

Table 4 Pulmonary Function Tests (Percentage Predicted Values) $(n=80)$

\begin{tabular}{|l|l|l|l|}
\hline & PRE-TAVR & POST-TAVR & p Value \\
\hline Total lung capacity (\%) & $64.56 \pm 2.84$ & $80.20 \pm 4.19$ & $<0.001$ \\
Residual Volume (\%) & $64.43 \pm 3.85$ & $75.73 \pm 5.26$ & $<0.001$ \\
FVC(\%) & $67.50 \pm 4.63$ & $74.46 \pm 5.74$ & $<0.001$ \\
FEVI(\%) & $59.54 \pm 3.43$ & $60.73 \pm 3.19$ & $<0.001$ \\
FEVI/FVC(\%) & $91.13 \pm 5.46$ & $88.33 \pm 5.33$ & 0.027 \\
DLCO (\%) & $42.40 \pm 4.62$ & $46.74 \pm 2.00$ & $<0.001$ \\
\hline
\end{tabular}

Note: Data is presented as means \pm SD or $n(\%)$.

Abbreviations: FVC, forced vital capacity; FEVI, forced expiratory volume in first second; DLCO, diffusing capacity of the lungs for carbon monoxide. 
11 months (range: $-0.8,-2.1$ class), $12-23$ months $(-0.8$, -2.1 class), $24-35$ months ( $-1.2,-2.6$ class), and $\geq 36$ months $(-1.2,-1.6$ class $)$. However, several studies ${ }^{28-31}$ showed a mean change of $<1$ NYHA class and the lower end of the $95 \%$ confidence interval near 0 , indicating that a large proportion of patients failed to improve after TAVR. We found only -0.51 class improvement at six months. This relatively low increase could be attributed to heart failure.

The average improvement in the NYHA class and pulmonary function does not necessarily mean that every individual derives the same benefit. Identifying patients who are most likely to have functional and pulmonary benefits is crucial to achieve optimal health outcomes and prevent avoidable harm.

Additionally, there is an increased usage of diuretics, beta-blockers, angiotensin-converting enzyme inhibitors, and angiotensin receptor blockers in post-TAVR patients. This has a positive impact on the NYHA class, ejection fraction, and pulmonary function.

This study was designed as a single-center, observational, retrospective study. Information was obtained from the electronic medical data. The limitations of this study include the subjectivity of pre- and post-TAVR pulmonary function tests and selection bias for TAVR. Further, large prospective studies may allow a better assessment of restrictive pulmonary function in patients with heart failure undergoing TAVR.

\section{Conclusions}

Pulmonary functions significantly improved in heart failure patients with a restrictive pattern undergoing TAVR.

\section{Funding}

This research did not receive any specific grants from funding agencies in the public, commercial, or not-forprofit sectors.

\section{Disclosure}

The authors reported no conflicts of interest for this work.

\section{References}

1. Hamm CW, Möllmann H, Holzhey D, et al. GARY-executive board. The German Aortic Valve Registry (GARY): in-hospital outcome. Eur Heart J. 2014;35(24):1588-1598. doi:10.1093/eurheartj/eht381

2. Di Mario C, Eltchaninoft H, Moat N, et al. The 2011-12 pilot European sentinel registry of transcatheter aortic valve implantation: in-hospital results in 4571 patients. Eurointervention. 2013;8:1362-1371. doi:10.4244/EIJV8I12A209
3. Moat NE, Ludman P, de Belder MA, et al. Long-term outcomes after transcatheter aortic valve implantation in high-risk patients with severe aortic stenosis: the U.K. TAVI (United Kingdom transcatheter aortic valve implantation) registry. J Am Coll Cardiol. 2011;58 (20):2130-2138. doi:10.1016/j.jacc.2011.08.050

4. Iung B, Laouenan C, Himbert D, et al. FRANCE 2 investigators. Predictive factors of early mortality after transcatheter aortic valve implantation: individual risk assessment using a simple score. Heart. 2014;100(13):1016-1023. doi:10.1136/heartjnl-2013-305314

5. Kurth L, Hnizdo E. Change in prevalence of restrictive lung impairment in the U.S. population and associated risk factors: the National Health and Nutritional Examination Survey (NHANES) 1988-1994 and 2007-2010. Multidiscip Respir Med. 2015;10:7. doi:10.1186/ s40248-015-0003-6

6. Guder G, Brenner S, Stork S, et al. Chronic obstructive pulmonary disease in heart failure: accurate diagnosis and treatment. Eur J Heart Fail. 2014;16(12):1273-1282. doi:10.1002/ejhf.183

7. Hankinson JL, Odencrantz JR, Fedan KB. Spirometric reference values from a sample of the general U.S. population. Am J Respir Crit Care Med. 1999;159(1):179-187. doi:10.1164/ajrccm.159.1.9 712108

8. Pellegrino R, Viegi G, Brusasco V, et al. Interpretative strategies for lung function tests. Eur Respir J. 2005;26:948-968. doi:10.1183/ 09031936.05 .00035205

9. Graham BL, Brusasco V, Burgos F, et al. 2017 ERS/ATS standards for single-breath carbon monoxide uptake in the lung. Eur Respir $J$. 2017;49(1):1600016. doi:10.1183/13993003.00016-2016

10. Roversi S, Fabbri LM, Sin DD, et al. Chronic obstructive pulmonary disease and cardiac diseases. An urgent need for integrated care. Am J Respir Crit Care Med. 2016;194(11):1319-1336. doi:10.1164/ rccm.201604-0690SO

11. Ayres SM. Mechanisms and consequences of pulmonary edema: cardiac lung, shock lung, and principles of ventilatory therapy in adult respiratory distress syndrome. Am Heart J. 1982;103 (1):97-112. doi:10.1016/0002-8703(82)90536-1

12. Daganou M, Dimopoulou I, Alivizatos PA, et al. Pulmonary function and respiratory muscle strength in chronic heart failure: comparison between ischaemic and idiopathic dilated cardiomyopathy. Heart. 1999;81(6):618-620. doi:10.1136/hrt.81.6.618

13. Mancini DM, Henson D, LaManca J, et al. Respiratory muscle function and dyspnea in patients with chronic congestive heart failure. Circulation. 1992;86(3):909-918. doi:10.1161/01. CIR.86.3.909

14. Olson TP, Beck KC, Johnson JB, et al. Competition for intrathoracic space reduces lung capacity in patients with chronic heart failure: a radiographic study. Chest. 2006;130(1):164-171. doi:10.1378/ chest.130.1.164

15. Magee MJ, Herbert MA, Roper KL, et al. Pulmonary function tests overestimate chronic pulmonary disease in patients with severe aortic stenosis. Ann Thorac Surg. 2013;96(4):1329-1335. doi:10.1016/j. athoracsur.2013.04.123

16. Gilmore RC, Thourani VH, Jensen HA, et al. Transcatheter aortic valve replacement results in improvement of pulmonary function in patients with severe aortic stenosis. Ann Thorac Surg. 2015;100 (6):2167-2173. doi:10.1016/j.athoracsur.2015.06.008

17. Bursi F, McNallan SM, Redfield MM, et al. Pulmonary pressures and death in heart failure. $J$ Am Coll Cardiol. 2012;59(3):222-231. doi:10.1016/j.jacc.2011.06.076

18. Malouf JF, Enriquez-Sarano M, Pellikka PA, et al. Severe pulmonary hypertension in patients with severe aortic valve stenosis: clinical profile and prognostic implications. J Am Coll Cardiol. 2002;40 (4):789-795. doi:10.1016/S0735-1097(02)02002-8

19. Park MH, Mehra MR. Pulmonary hypertension: the great leveler. $J$ Am Coll Cardiol. 2012;59(3):232-234. doi:10.1016/j. jacc.2011.09.052 
20. Ussia GP, Barbanti M, Colombo A, et al. Impact of coronary artery disease in elderly patients undergoing transcatheter aortic valve implantation: insight from the Italian CoreValve Registry. Int J Cardiol. 2013;167(3):943-950. doi:10.1016/j.ijcard.2012.03.089

21. Abdel-Wahab M, Mostafa AE, Geist V, et al. Comparison of outcomes in patients having isolated transcatheter aortic valve implantation versus combined with preprocedural percutaneous coronary intervention. Am J Cardiol. 2012;109(4):581-586. doi:10.1016/j. amjcard.2011.09.053

22. Buellesfeld L, Gerckens U, Schuler G, et al. 2-year follow-up of patients undergoing transcatheter aortic valve implantation using a self-expanding valve prosthesis. J Am Coll Cardiol. 2011;57 (16):1650-1657. doi:10.1016/j.jacc.2010.11.044

23. D'Onofrio A, Gasparetto V, Napodano M, et al. Impact of preoperative mitral valve regurgitation on outcomes after transcatheter aortic valve implantation. Eur J Cardiothorac Surg. 2012;41(6):1271-1277. doi:10.1093/ejcts/ezr236

24. Ewe SH, Muratori M, Delgado V, et al. Hemodynamic and clinical impact of prosthesis-patient mismatch after transcatheter aortic valve implantation. $J$ Am Coll Cardiol. 2011;58(18):1910-1918. doi:10.1016/j.jacc.2011.08.027

25. Gautier M, Pepin M, Himbert D, et al. Impact of coronary artery disease on indications for transcatheter aortic valve implantation and on procedural outcomes. EuroIntervention. 2011;7(5):549-555. doi:10.4244/EIJV7I5A90
26. Gotzmann M, Lindstaedt M, Bojara W, et al. Clinical outcome of transcatheter aortic valve implantation in patients with low-flow, low gradient aortic stenosis. Catheter Cardiovasc Interv. 2012;79 (5):693-701. doi:10.1002/ccd.23240

27. Hutter A, Bleiziffer S, Richter V, et al. Transcatheter aortic valve implantation in patients with concomitant mitral and tricuspid regurgitation. Ann Thorac Surg. 2013;95(1):77-84. doi:10.1016/j. athoracsur.2012.08.030

28. Gotzmann M, Bojara W, Lindstaedt M, et al. One-year results of transcatheter aortic valve implantation in severe symptomatic aortic valve stenosis. Am J Cardiol. 2011;107(11):1687-1692. doi:10.1016/ j.amjcard.2011.01.058

29. Ye J, Cheung A, Lichtenstein SV, et al. Transapical transcatheter aortic valve implantation: follow-up to 3 years. $J$ Thorac Cardiovasc Surg. 2010;139(5):1107-1113. doi:10.1016/j. jtcvs.2009.10.056

30. Chodor P, Wilczek K, Przybylski R, et al. Immediate and 6-month outcomes of transapical and transfemoral Edwards-Sapien prosthesis implantation in patients with aortic stenosis. Kardiol Pol. 2010;68 (10):1124-1131.

31. Schoenenberger AW, Stortecky S, Neumann S, et al. Predictors of functional decline in elderly patients undergoing transcatheter aortic valve implantation (TAVI). Eur Heart J. 2013;34(9):684-692. doi:10.1093/eurheartj/ehs304
International Journal of General Medicine

\section{Publish your work in this journal}

The International Journal of General Medicine is an international, peer-reviewed open-access journal that focuses on general and internal medicine, pathogenesis, epidemiology, diagnosis, monitoring and treatment protocols. The journal is characterized by the rapid reporting of reviews, original research and clinical studies

\section{Dovepress}

across all disease areas. The manuscript management system is completely online and includes a very quick and fair peer-review system, which is all easy to use. Visit http://www.dovepress.com/ testimonials.php to read real quotes from published authors. 